\title{
Coffee, Tea and Their Additives: Association with BMI and Waist Circumference
}

\author{
Danielle R. Bouchard ${ }^{a}$ Robert Ross ${ }^{a}$ lan Janssen ${ }^{a, b}$ \\ a School of Kinesiology and Health Studies, \\ ${ }^{\mathrm{b}}$ Department of Community Health Epidemiology, Queen's University, Kingston, ON, Canada
}

\section{Keywords}

Obesity · Caffeine $\cdot$ Whitener $\cdot$ Sweetener

\section{Summary}

Objective: The purposes of this study were to perform a detailed analysis how: i) the frequency of coffee/tea consumption and ii) the use of additives in coffee/tea is associated with measures of total and abdominal obesity. Method: 3,823 participants of the 2003-2004 National Health and Nutrition Examination Survey were examined. Obesity was assessed by BMI and waist circumference (WC). Coffee and tea consumption and use of additives were assessed by questionnaire. Results: Coffee consumption was not related to BMI or WC in either gender. However, men who drank $\geq 2$ cups of tea per day had lower BMI (25.9 vs. $28.0 \mathrm{~kg} / \mathrm{m}^{2}$ ) and WC (95.2 vs. $101.32 \mathrm{~cm}$ ) values than men who never drank drink tea ( $p \leq 0.05$ ). The associations between tea consumption and $\mathrm{BMI}$ or WC were no longer significant after adjustment for additive use. Coffee/tea drinkers who used artificial sweeteners had larger ( $p \leq 0.05$ ) BMls than coffee/ tea drinkers who did not use sweeteners (28.2 vs. 27.1 $\mathrm{kg} / \mathrm{m}^{2}$ in men, $28.4 \mathrm{vs} .27 .1 \mathrm{~kg} / \mathrm{m}^{2}$ in women). Conclusion: Frequency of coffee/tea consumption was not associated with measures of obesity because additive use explained the association between tea consumption and obesity in men. Artificial sweetener use within coffee/tea was associated with higher BMI.

\section{Introduction}

More than $55 \%$ of the adult population drinks coffee or tea $[1,2]$. There is consistent epidemiological evidence that consumption of these hot beverages is associated with a reduced risk of type 2 diabetes and coronary heart disease [3, 4]. It has been hypothesized that the protective effect of coffee and tea consumption on type 2 diabetes risk is mediated by a reduction in obesity [5]. This hypothesis is supported by a handful of clinical intervention studies which report that the frequency of coffee or tea consumption is related to weight loss and change in body fat distribution [6-10]. However, there is inconsistency in the literature as numerous observational studies have found that coffee and/or tea consumption are not associated with obesity [11-14]. These inconsistencies may partially be explained by the fact that most of the previous studies did not thoroughly investigate the association between coffee/tea consumption and obesity; the main focus of these studies was the association between hot beverage consumption and type 2 diabetes risk $[11-13,15]$.

Although abdominal obesity is a phenotype that poses an important health risk [16], few studies have investigated the association between coffee and/or tea consumption and abdominal obesity [8,17-19], and the results of these studies are inconsistent. For example, Balk et al. [17] report no association between waist circumference and long-term coffee consumption in a European cohort while Hino et al. [18] reported that coffee, but not tea, consumption was associated to lower waistline in a Japanese sample.

There are several mechanisms that may explain the association between coffee or tea consumption with total and abdominal obesity. Caffeine contained in coffee and tea, or simply drinking coffee or tea per se, is associated with a higher resting metabolic rate [20,21], a greater satiety level

\begin{tabular}{ll}
\hline KARGER & $\oplus$ 2010 S. Karger GmbH, Freiburg \\
Fax +497614520714 & Accessible online at: \\
Information@Karger.de & www.karger.com/ofa \\
www.karger.com &
\end{tabular}


[22] and a higher thermogenesis level [20, 23]. In addition, the chlorogenic acid present in coffee and black tea influences the absorption and utilization of glucose from the diet $[6,9]$. Furthermore, as coffee and tea can be consumed as frequently as 10 times per day [12], it is reasonable to speculate that the use of calorically rich additives in hot beverages, such as cream and sugar, may cumulatively have an impact on obesity.

To our knowledge only one study has considered the influence of coffee and tea additives on obesity [24], this despite the fact that a high percentage of coffee and tea drinkers put additives in these hot beverages. Contrary to expectations, that study reports that men who added sugar to their coffee or tea had BMI values that were $1.1 \mathrm{~kg} / \mathrm{m}^{2}$ lower than those who did not add sugar to their coffee or tea [24]. Further consideration needs to be given to sugar and other additives such as milk, cream and artificial sweeteners.

The purposes of this study were to i) perform a detailed analysis of the associations between the frequency of coffee and tea consumption and measures of total and abdominal obesity and ii) examine the association between the use of additives in coffee and tea and measures of total and abdominal obesity. We examined these associations within a large sample of American adults.

\section{Material and Methods}

\section{Study Population}

The study sample consisted of individuals aged 18 years and older who participated in the 2003-2004 cycle of the National Health and Nutrition Examination Survey (NHANES). This cross-sectional survey was completed in the non-institutionalized US population. Subjects were identified using a complex, stratified, multistage, probability sampling design. Detailed survey operations manuals, consent documents and brochures of the study are available on the NHANES website $[25,26]$. Briefly, there were two parts to the study: a home interview and a thorough health examination. During the home interview, participants were asked questions about their health status, disease history and lifestyle behaviors. The health examination was performed in a mobile exam center where the food frequency questionnaire and anthropometric measures were completed.

The protocol was approved by the National Center for Health Statistics and all participants provided informed consent. Of the original sample aged 18 years and older who completed the mobile exam center visit $(\mathrm{N}=5,303), 3,823$ individuals had complete information on the exposures and outcomes of interests and were retained for the analyses. The participants who were excluded from the present paper were similar in gender ( $54.5 \%$ vs. $54.1 \%$ women) but were slightly younger $(43.9 \pm 21.4$ vs. $48.7 \pm 20.6$ years) than the participants that were included.

\section{Obesity Measures}

Height (to the nearest $0.1 \mathrm{~cm}$ ) and weight (to the nearest $0.1 \mathrm{~kg}$ ) were measured using a fixed stadiometer and a digital scale (Toledo digital scale), respectively. These values were used to calculate the BMI $\left(\mathrm{kg} / \mathrm{m}^{2}\right)$, which was used as a measure of total obesity. Abdominal obesity was assessed using the waist circumference (WC), which was measured to the nearest $0.1 \mathrm{~cm}$ using a steel measuring tape at the high point of the iliac crest at minimal respiration.

\section{Coffee and Tea Consumption}

The frequency of coffee consumption was assessed using the following question: 'Over the past 12 months, how many cups of hot coffee, caffeinated or decaffeinated, did you drink?' The possible responses were: 'never', 'less than 1 cup per month', ' 1 to 3 cups per month', ' 1 cup per week', '2 to 4 cups per week', ' 5 to 6 cups per week', ' 1 cup per day', ' 2 to 3 cups per day', ' 4 to 5 cups per day', and ' 6 or more cups per day'. The same question was asked to assess the frequency of hot tea consumption.

\section{Coffee and Tea Additives}

Four additives were assessed: i) milk, ii) cream, iii) sugar or honey, and iv) artificial sweetener. The following question was asked for each additive 'How often did you add (milk, cream, sugar or honey, artificial sweetener) to your coffee/tea?' The possible responses for each question were: 'never', 'less than 1 time per month', ' 1 to 3 times per month', ' 1 time per week', '2 to 4 times per week', '5 to 6 times per week', ' 1 time per day', ' 2 to 3 times per day', ' 4 to 5 times per day', and ' 6 or more times per day'.

\section{Total Caffeine and Caffeine within Coffee and Tea}

Total dietary caffeine content was measured from a 24-hour food recall [27]. In addition, amongst coffee and tea drinkers, caffeine use within hot beverages was self-reported for each type of beverage using the following question: 'Over the past 12 months, how often was the (coffee, tea) you drank decaffeinated?' The possible responses were: 'almost never or never', 'about $1 / 4$ of the time', 'about $1 / 2$ of the time', 'about $3 / 4$ of the time', and 'almost always or always'. Coffee and tea drinkers who responded 'about $3 / 4$ of the time' or 'almost always or always' were considered as drinking primarily decaffeinate hot beverages for the statistical analyses.

\section{Covariates}

Age was included as a continuous variable. Ethnicity was categorized into four groups (non-Hispanic white, non-Hispanic black, Hispanic and other). Participants were asked whether or not they were engaged in 48 different leisure-time activities in the previous month (e.g. walking, gardening, etc.). Information about the frequency and duration of engagement in these activities were used to create the following physical activity groups: 'never', '<30 min/day', '30-59 min/day' and ' $\geq 60 \mathrm{~min} /$ day'. Subjects were considered current smokers if they smoked cigarettes at the time of the survey, former smokers if they were not currently smoking but had smoked more than 100 cigarettes in their life, and non-smokers if they smoked less than this amount. Alcohol intake was calculated based on mean number of reported alcoholic drinks per day as: 'never', ' $<1$ drink/day', '1-2 drinks/day', and ' $>2$ drinks/day'. Total energy intake (kcal) as well as quality of the participants' diet was based on a 24-hour food recall [27]. The quality of the participants' diets was assessed based on adherence to the United States Department of Agriculture recommendations for seven different dietary components [28]: protein (10-35\% of total calories), carbohydrate (40-45\% of total calories), total fat (20$35 \%$ of total calories), saturated fat ( $<10 \%$ of total calories), cholesterol ( $<300 \mathrm{mg} /$ day), fiber ( $>25 \mathrm{~g} /$ day for women, $>30 \mathrm{~g} /$ day for men), and sodium $(<2,400 \mathrm{mg} /$ day $)$. A score of 1 was given if an individual met the recommendation for each of the seven components of the participant's diet (protein, carbohydrate, total fat, saturated fat, cholesterol, fiber and sodium). A sum of these components was then computed to create a diet quality index with values ranging from 0 to 7 .

\section{Statistical Analysis}

Descriptive analyses were used to characterize the distribution of key study variables. Differences in characteristics between coffee/tea drinkers and non-drinkers were assessed by unpaired T-tests (continuous variables) and $\chi^{2}$ tests (categorical variables).

Within coffee and tea drinkers, participants were placed into 5 groups, depending on the type of hot beverage consumed. A ratio score based on 
Table 1. Descriptive characteristics of sample*

\begin{tabular}{|c|c|c|c|}
\hline & $\begin{array}{l}\text { Total } \\
(\mathrm{N}=3,823)\end{array}$ & $\begin{array}{l}\text { Coffee/tea drinkers } \\
(\mathrm{N}=3,213)\end{array}$ & $\begin{array}{l}\text { Non-drinkers } \\
(\mathrm{N}=610)\end{array}$ \\
\hline Women, \% & 54.1 & 54.4 & 54.9 \\
\hline Age, years & $48.7 \pm 20.6$ & $51.1 \pm 20.2$ & $36.2 \pm 18.3^{\mathrm{a}}$ \\
\hline $\mathrm{BMI}, \mathrm{kg} / \mathrm{m}^{2}$ & $28.3 \pm 6.4$ & $28.1 \pm 6.2$ & $29.0 \pm 7.4$ \\
\hline Waist circumference, $\mathrm{cm}$ & $97.7 \pm 15.6$ & $97.6 \pm 15.4$ & $97.7 \pm 16.6$ \\
\hline Caffeine intake, mg/day & $154.5 \pm 211.9$ & $169.1 \pm 220.9$ & $77.70 \pm 131.8^{\mathrm{a}}$ \\
\hline \multicolumn{4}{|l|}{ Ethnicity, \% } \\
\hline Non-Hispanic white & 54.8 & 55.7 & $49.5^{\mathrm{a}}$ \\
\hline Non-Hispanic black & 18.9 & 17.2 & $28.4^{\mathrm{a}}$ \\
\hline Hispanic & 22.5 & 23.1 & $19.0^{\mathrm{a}}$ \\
\hline Other & 3.9 & 3.9 & 3.1 \\
\hline \multicolumn{4}{|l|}{ Smoking, \% } \\
\hline Never smoker & 50.4 & 48.9 & $59.7^{\mathrm{a}}$ \\
\hline Former smoker & 28.7 & 30.2 & $18.8^{\mathrm{a}}$ \\
\hline Current smoker & 20.9 & 20.9 & 21.5 \\
\hline \multicolumn{4}{|l|}{ Physical activity, \% } \\
\hline Never & 38.8 & 39.2 & 36.3 \\
\hline$<30 \mathrm{~min} /$ day & 31.8 & 32.3 & 29.3 \\
\hline $30-59 \mathrm{~min} /$ day & 13.2 & 13.1 & 13.9 \\
\hline$\geq 60 \mathrm{~min} /$ day & 16.1 & 15.3 & $20 .^{4 a}$ \\
\hline \multicolumn{4}{|l|}{ Alcohol, \% } \\
\hline Never & 27.9 & 27.5 & 30.2 \\
\hline$<1$ drink/day & 59.8 & 60.4 & 55.4 \\
\hline 1-2 drinks/day & 7.4 & 7.1 & 9.3 \\
\hline$>2$ drinks/day & 4.9 & 4.9 & 5.1 \\
\hline Healthy food index $(0-7)$ & $2.9 \pm 1.3$ & $2.9 \pm 1.3$ & $2.9 \pm 1.2$ \\
\hline Total caloric intake, kcal/day & $2,142.7 \pm 1,003.8$ & $2,102.5 \pm 966.9$ & $2,354.4 \pm 1,157.0^{\mathrm{a}}$ \\
\hline
\end{tabular}

*Data presented as unadjusted mean \pm SD for continuous variables or prevalence (\%) for categorical variables.

aSignificant difference between unadjusted means coffee/tea drinkers and non-drinkers $(\mathrm{p} \leq 0.05)$.

the frequency of coffee and tea consumption was used to create these 5 groups: i) equal coffee and tea (ratio $0.79-1.19$ ), ii) mostly coffee (ratio $\geq 1.2$ ), iii) mostly tea (ratio $\leq 0.8$ ), iv) only coffee and v) only tea. Differences in descriptive characteristics between these 5 groups were assessed using generalized linear models (GLM) with Bonferonni post hoc comparisons. Age, gender, ethnicity, smoking, alcohol, physical activity, diet quality index, total caloric intake and the frequency of coffee and tea consumption were included as covariates in the GLM models.

The associations between the frequency of coffee and tea consumption with the obesity measures was determined using GLM with Bonferonni post hoc comparisons. Despite a close correlation between BMI and WC (men: $r=0.91$, women: $r=0.90$ ) both were tested separately because of their independent relationship with several health outcomes. For this analysis, 4 groups were created based on the frequency of coffee or tea consumption: i) never ('never' or 'less than 1 cup per month'), ii) occasional (' 1 to 3 cups per month' to ' 2 to 4 cups per week'), iii) regular (' 5 to 6 cups per week' or ' 1 cup per day'), and iv) frequent ('2 to 3 cups per day' to ' 6 or more cups per day'). Four GLM models were run for BMI and WC to consider the impact of different covariates on the observed relationships. Model 1 included age, gender, ethnicity, smoking, alcohol, physical activity, diet quality index and total caloric intake as covariates.
Model 2 included the covariates in Model 1 plus caffeine intake. Model 3 included the covariates in Model 2 plus the whitener and sweetener additives.

Finally, the association between the use of whitener and sweetener additives with BMI and WC within the coffee and tea drinkers was determined using GLM with Bonferonni post hoc comparisons. Analyses suggested that treating the additives as dichotomous variables provided the same results as when the additives were treated as continuous variables based on the original 10-point response options (data not shown). Thus, to make the results more applicable for public health use, the additives were each treated as dichotomous (yes or no) variables. Coffee and tea consumers were placed into groups based on their overall use of sweetener (none, only artificial sweetener, only sugar/honey, both artificial sweetener and sugar/honey) and whitener (none, only milk, only cream, both milk and cream) additives. BMI and WC values were compared across the 4 whitener groups and the 4 sweetener groups. Covariates in the GLM models included age, ethnicity, smoking, alcohol, physical activity, diet quality index, total caloric intake, frequency of coffee and tea consumption, and caffeine content of coffee and tea. Sweetener use was also adjusted for in the whitener analyses, and whitener use was also adjusted for in the sweetener analyses. 
Table 2. Descriptive characteristics of coffee and/or tea drinkers*

\begin{tabular}{|c|c|c|c|c|c|}
\hline & $\begin{array}{l}\text { Equal coffee and tea } \\
(\mathrm{N}=579)\end{array}$ & $\begin{array}{l}\text { Mostly coffee } \\
(\mathrm{N}=947)\end{array}$ & $\begin{array}{l}\text { Mostly tea } \\
(\mathrm{N}=132)\end{array}$ & $\begin{array}{l}\text { Only coffee } \\
(\mathrm{N}=1121)\end{array}$ & $\begin{array}{l}\text { Only tea } \\
(\mathrm{N}=434)\end{array}$ \\
\hline Women, \% & $59.3^{\mathrm{d}}$ & 58.3 & $64.4^{\mathrm{d}}$ & $43.2^{\mathrm{a}, \mathrm{c}, \mathrm{e}}$ & $64.5^{\mathrm{d}}$ \\
\hline Age, years & $45.2 \pm 20.7^{\mathrm{b}, c, d}$ & $56.6 \pm 7.8^{\mathrm{a}, \mathrm{d}, \mathrm{e}}$ & $54.7 \pm 20.9^{\mathrm{a}, \mathrm{e}}$ & $52.1 \pm 19.9^{\mathrm{a}, \mathrm{b}, \mathrm{e}}$ & $43.4 \pm 20.5^{b, c, d}$ \\
\hline Total caloric intake, $\mathrm{kcal} / \mathrm{day}$ & $2,354.4 \pm 1,157.0^{\mathrm{b}}$ & $2,027.6 \pm 896.4^{\text {a.d }}$ & $2,030.5 \pm 837.4$ & $2,117.9 \pm 970.5^{\mathrm{b}}$ & $2,157.8 \pm 1,007.7$ \\
\hline Diet quality index $(0-7)$ & $3.1 \pm 1.2^{\mathrm{b}, \mathrm{d}}$ & $2.9 \pm 1.3^{\mathrm{a}}$ & $3.2 \pm 1.2^{\mathrm{d}}$ & $2.9 \pm 1.3^{\mathrm{a}, \mathrm{c}}$ & $2.9 \pm 1.3$ \\
\hline Caffeine intake, mg/day & $99.2 \pm 150.9^{\mathrm{b}, \mathrm{d}, \mathrm{e}}$ & $222.7 \pm 218.5^{\mathrm{a}, \mathrm{c}, \mathrm{d}, \mathrm{e}}$ & $114.8 \pm 118.8^{\mathrm{b}, \mathrm{d}, \mathrm{e}}$ & $204.8 \pm 268.2^{\mathrm{a}, \mathrm{b}, \mathrm{c}, \mathrm{e}}$ & $69.3 \pm 99.8^{\mathrm{a}, \mathrm{b}, \mathrm{c}, \mathrm{d}}$ \\
\hline \multicolumn{6}{|l|}{ Obesity measures ${ }^{\dagger \ddagger}$} \\
\hline $\mathrm{BMI}, \mathrm{kg} / \mathrm{m}^{2}$ & $28.3 \pm 6.6$ & $28.3 \pm 5.8$ & $26.7 \pm 6.3$ & $28.3 \pm 6.0$ & $26.9 \pm 7.2$ \\
\hline Waist circumference, $\mathrm{cm}$ & $96.2 \pm 15.7^{\mathrm{b}, \mathrm{c}, \mathrm{d}, \mathrm{e}}$ & $98.2 \pm 13.9^{\mathrm{a}, \mathrm{c}, \mathrm{d}, \mathrm{e}}$ & $93.9 \pm 15.9^{\mathrm{a}, \mathrm{b}, \mathrm{c}, \mathrm{e}}$ & $99.4 \pm 15.4^{\mathrm{a}, \mathrm{b}, \mathrm{c}, \mathrm{e}}$ & $95.0 \pm 16.9^{\mathrm{a}, \mathrm{b}, \mathrm{d}}$ \\
\hline \multicolumn{6}{|l|}{ Coffee/tea information ${ }^{\dagger}$} \\
\hline Number of cups/day & $1.9 \pm 0.9^{\mathrm{b}, \mathrm{d}, \mathrm{e}}$ & $2.2 \pm 0.9^{\mathrm{a}, \mathrm{c}, \mathrm{d}, \mathrm{e}}$ & $2.2 \pm 1.0^{\mathrm{b}, \mathrm{d}}$ & $1.2 \pm 0.7^{\mathrm{a}, \mathrm{b}, \mathrm{ce}, \mathrm{e}}$ & $1.0 \pm 0.6^{\mathrm{a}, \mathrm{b}, \mathrm{d}}$ \\
\hline Mostly drink decaffeinate coffee/tea, \% & 29.5 & $22.0^{\mathrm{c}, \mathrm{e}}$ & $33.3^{\mathrm{b}, \mathrm{e}}$ & 27.8 & $58.1^{\mathrm{b}, \mathrm{c}}$ \\
\hline Add sugar/honey, \% & $73.6^{\mathrm{c}}$ & 61.8 & 60.6 & $55.2^{\mathrm{a}}$ & 68.2 \\
\hline Add artificial sweetener, $\%$ & $42.1^{\mathrm{b}}$ & $36.6^{\mathrm{a}}$ & 34.9 & 32.2 & 27.2 \\
\hline Add milk, \% & $64.2^{\mathrm{d}, \mathrm{e}}$ & 51.3 & $67.4^{\mathrm{d}, \mathrm{e}}$ & $42.5^{\mathrm{a,c}}$ & $26.3^{\mathrm{a}, \mathrm{c}}$ \\
\hline Add cream, \% & $37.7^{\mathrm{d}, \mathrm{e}}$ & $33.4^{\mathrm{e}}$ & $34.1^{\mathrm{e}}$ & $24.0^{\mathrm{a}, \mathrm{e}}$ & $7.1^{\mathrm{a}, \mathrm{b}, \mathrm{c}, \mathrm{d}}$ \\
\hline
\end{tabular}

*Data presented as unadjusted mean $\pm \mathrm{SD}$ for continuous variables or prevalence $(\%)$ for categorical variables.

${ }^{\dagger}$ Analyses adjusted for age, gender, ethnicity, smoking, alcohol, physical activity, diet quality index, total caloric intake, and the frequency of coffee and tea consumption.

${ }^{\ddagger}$ Further adjustment for caffeine intake.

Statistically different $(\mathrm{p} \leq 0.05)$ from the: ${ }^{\mathrm{a} e q u a l}$ coffee and tea group, ${ }^{\mathrm{b}}$ mostly coffee group, ${ }^{\mathrm{c}}$ mostly tea group, ${ }^{\mathrm{d}}$ only coffee group, ${ }^{\mathrm{o}}$ only tea group.

All data management and statistical analyses were performed in SAS version 9.1 (SAS Institute, Carry, NC, USA). Statistics accounted for the sample weights and complex design (strata, probability sampling units) of the NHANES survey. Interaction tests (effect modification) were conducted for age, sex, physical activity, ethnicity and smoking. As the gender interaction terms were significant, all of the primary analyses were performed separately in men and women.

\section{Results}

\section{Descriptive Characteristics}

Of the 3,823 participants, 3,213 were coffee and/or tea drinkers and 610 were non-drinkers (table 1 ). The mean age of the sample was $49 \pm 21$ years. Slightly more than half of the sample was female $(54.1 \%)$ and non-Hispanic white $(54.8 \%)$. Coffee/tea drinkers were older, were more likely to be a former smoker and were less likely to participate in more than $60 \mathrm{~min} /$ day of physical activity in comparison with nondrinkers. Moreover, ethnic differences were observed between coffee/tea drinkers and non-drinkers ( $\mathrm{p} \leq 0.05)$.

Additionnal descriptive information on the 3,213 coffee/tea drinkers according to the type of hot beverage they consumed is shown in table 2. Amongst the coffee and tea drinkers, $34.9 \%$ only drank coffee, $13.5 \%$ only drank tea and $51.6 \%$ drank both hot beverages. The 'mostly tea' or 'only tea' groups had lower waist circumference values than the 'mostly coffee' or 'only coffee' groups (all p $\leq 0.05$ ). Finally, compared with the 'equal coffee/tea' group, the 'only coffee' group reported adding less sugar/honey, while the 'mostly coffee' group reported adding less artificial sweetener. Finally the 'only coffee' and 'only tea' groups reported adding less milk and cream than the 'equal coffee/tea' group (all $\mathrm{p} \leq 0.05$ ).

\section{Association between Coffee/Tea Consumption with BMI and $W C$}

Unadjusted mean BMI values were not significantly different across the four coffee and tea frequency groups in both men and women. However, after adjustment for age, ethnicity, smoking status, alcohol intake, physical activity level, the diet quality index and total calorie intake (Model 1, table 3), mean BMI value was higher in men who never drink tea $(28.36$ $\pm 5.61 \mathrm{~kg} / \mathrm{m}^{2}$ ) compared with that of men who drank tea frequently $\left(25.85 \pm 5.60 \mathrm{~kg} / \mathrm{m}^{2} ; \mathrm{p} \leq 0.01\right)$. The results were similar for Model 2, which also adjusted for caffeine intake. However, after further adjustment for whitener and sweetener additives in Model 3, the mean BMI values amongst the men were no longer statistically different across the tea consumption groups.

Similar to results with BMI, mean unadjusted WC values were not significantly different across the four coffee and tea frequency groups in both men and women. However, after adjustment for adjusted for age, ethnicity, smoking, alcohol, physical activity, diet quality index and total calorie intake, mean WC value was higher in men who never drink tea $(101.47 \pm 14.31 \mathrm{~cm})$ compared with that of men who drank 
Table 3. Association between the frequency of coffee and tea consumption with BMI*

\begin{tabular}{llll}
\hline & Model 1 & Model 2 & Model 3 \\
\hline Men & & & \\
Coffee consumption & & & \\
$\quad$ Never $(\mathrm{N}=429)$ & $27.88 \pm 5.99$ & $28.03 \pm 6.10$ & $27.78 \pm 11.14$ \\
Occasional $(\mathrm{N}=366)$ & $27.92 \pm 5.80$ & $28.06 \pm 5.90$ & $28.63 \pm 5.67$ \\
Regular $(\mathrm{N}=356)$ & $27.69 \pm 5.71$ & $27.71 \pm 5.91$ & $27.77 \pm 5.36$ \\
Frequent $(\mathrm{N}=389)$ & $28.28 \pm 5.98$ & $28.07 \pm 6.34$ & $28.01 \pm 5.83$ \\
Tea consumption & & & \\
Never $(\mathrm{N}=912)$ & $28.36 \pm 5.61^{\mathrm{b}}$ & $28.34 \pm 5.60^{\mathrm{b}}$ & $28.01 \pm 8.91$ \\
Occasional $(\mathrm{N}=667)$ & $27.78 \pm 5.62$ & $27.79 \pm 5.62$ & $27.92 \pm 6.60$ \\
Regular $(\mathrm{N}=103)$ & $27.19 \pm 5.51$ & $27.22 \pm 5.50$ & $27.50 \pm 6.50$ \\
Frequent $(\mathrm{N}=58)$ & $25.85 \pm 5.60^{\mathrm{a}}$ & $25.82 \pm 5.60^{\mathrm{a}}$ & $26.91 \pm 7.71$ \\
\hline Women & & & \\
Coffee consumption & & & \\
Never $(\mathrm{N}=615)$ & $29.17 \pm 7.30$ & $29.26 \pm 7.50$ & $27.78 \pm 11.14$ \\
Occasional $(\mathrm{N}=491)$ & $28.60 \pm 6.99$ & $28.63 \pm 7.07$ & $28.63 \pm 7.09$ \\
Regular $(\mathrm{N}=452)$ & $28.19 \pm 7.36$ & $28.25 \pm 7.00$ & $28.36 \pm 6.76$ \\
Frequent $(\mathrm{N}=525)$ & $28.19 \pm 7.36$ & $28.11 \pm 7.93$ & $28.23 \pm 7.23$ \\
Tea Consumption & & & \\
Never $(\mathrm{N}=819)$ & $28.51 \pm 6.87$ & $28.51 \pm 6.87$ & $28.20 \pm 8.91$ \\
Occasional $(\mathrm{N}=965)$ & $28.83 \pm 6.86$ & $28.63 \pm 6.87$ & $28.77 \pm 6.60$ \\
Regular $(\mathrm{N}=198)$ & $28.50 \pm 6.70$ & $28.51 \pm 6.70$ & $28.25 \pm 6.50$ \\
Frequent $(\mathrm{N}=101)$ & $27.44 \pm 6.77$ & $27.40 \pm 6.80$ & $27.20 \pm 6.71$ \\
\hline
\end{tabular}

*Data presented as adjusted mean $\pm \mathrm{SD}$. Model 1 was adjusted for age, ethnicity, smoking status, alcohol intake, physical activity level, the diet quality index and, total calorie intake. The coffee analyses were also adjusted for the frequency of tea consumption, and the tea analyses were adjusted for the frequency of coffee consumption. Model 2 adjusted for covariates in Model $1+$ caffeine intake. Model 3 adjusted for covariates in Model 2 + whitener and sweetener additive use.

aSignificantly different from the 'never' group $(\mathrm{p}<0.05)$.

'Significantly different from the 'frequent' group $(\mathrm{p}<0.05)$.

tea occasionally $(99.45 \pm 14.31 \mathrm{~cm} ; \mathrm{p}=0.04)$, regularly $(97.06$ $\pm 14.21 \mathrm{~cm} ; \mathrm{p}=0.02)$ and frequently $(95.17 \pm 14.23 \mathrm{~cm} ; \mathrm{p} \leq 0.01)$ (Model 1, table 4). The results were similar for Model 2, which also adjusted for caffeine intake. Finally, after further adjustment for whitener and sweetener additives in Model 3, the mean WC values amongst the men were no longer statistically different across tea consumption groups.

Association between Coffee/Tea Additives with BMI and WC The remaining analyses were limited to the 3,213 coffee/tea drinkers. These analyses were controlled for several covariates, as shown in the legends of table 5. In men, those who did not add a sweetener to their coffee/tea had higher mean BMI values $\left(27.1 \pm 14.5 \mathrm{~kg} / \mathrm{m}^{2}\right)$ than those who added sugar/honey $\left(26.1 \pm 16.8 \mathrm{~kg} / \mathrm{m}^{2} ; \mathrm{p}=0.04\right)$ and lower mean BMI values than those who added an artificial sweetener $\left(28.8 \pm 10.4 \mathrm{~kg} / \mathrm{m}^{2}\right.$; $\mathrm{p}=0.02)$. Similarly, men who did not add a sweetener to their coffee/tea had a lower mean WC than those who added an artificial sweetener $(97.4 \pm 27.6$ vs. $102.1 \pm 20.8 \mathrm{~cm}$; $\mathrm{p} \leq 0.01)$.
In women, those who did not add a sweetener to their coffee/ tea had a lower mean BMI than women who added an artificial sweetener $\left(27.1 \pm 15.4\right.$ vs. $\left.28.8 \pm 13.3 \mathrm{~kg} / \mathrm{m}^{2}, \mathrm{p}=0.03\right)$. Unlike men, no associations between the type of sweetener and WC were observed in women. Finally, within both sexes, the use of whiteners (milk, cream, or both) was not independently associated with BMI or WC.

\section{Discussion}

Within both men and women, the frequency of coffee consumption was not associated with BMI or WC. However, the frequency of tea consumption was negatively associated with BMI and WC in men. This association was no longer significant after adjusting for additive use, suggesting that additive use in large measures explains the association between tea consumption and obesity. Surprisingly, coffee and tea drinkers who added artificial sweeteners to their beverages had higher BMI (men and women) and WC values (only in men) compared to those who never used sweeteners, while those who added sugar/honey also had lower BMI values.

Our finding that coffee consumption was not associated with BMI or WC is supported by Balk et al. [17] who reported similar findings in a 15-year longitudinal study of 283 American men and women. These findings do, however, contrast with those of Hino et al. [18] who reported, in a cross-sectional study of 1,902 Japanese men and women aged over 40 or older, that coffee consumption was negatively associated with WC. This discrepancy may be explained by the fact that the frequency of coffee consumption is lower in Japan than in the USA [29].

We observed that men who drank more than 2 cups of tea per day had significantly lower mean BMI values than nonconsumers ( 25.9 vs. $28.3 \mathrm{~kg} / \mathrm{m}^{2}$ ) before adjusting for coffee/tea additives. The relation between tea consumption and BMI was not observed in women. Men and women have differences in other behaviors such as exercise, smoking, alcohol and diet quality $[30,31]$ that could perhaps modify the association between tea consumption and obesity and account for the gender difference observed in our study. Our findings in men are consistent with the findings of two short-term intervention studies that were based on animal and human models and did not consider additives [7, 8]. Both of these studies reported that Oolong tea consumption decreases body weight and fat by increasing lipid oxidation. Regarding the impact of tea consumption on WC, we report a significant negative association of frequent tea consumption, but only in men. Conversely, Wu et al. [19] reported an association between tea consumption and WC in women, but not in men, while He et al. [8] reported an association between tea consumption and WC in both genders. The discrepancy regarding the gender divergence between tea consumption and $\mathrm{WC}$, and the discrepancy between studies around this gender difference, are 
Table 4. Association between the frequency of coffee and tea consumption with waist circumference*

\begin{tabular}{|c|c|c|c|}
\hline & Model 1 & Model 2 & Model 3 \\
\hline \multicolumn{4}{|l|}{ Men } \\
\hline \multicolumn{4}{|l|}{ Coffee consumption } \\
\hline Never $(\mathrm{N}=429)$ & $100.00 \pm 15.35$ & $99.30 \pm 15.42$ & $98.92 \pm 22.00$ \\
\hline Occasional $(\mathrm{N}=366)$ & $100.25 \pm 14.93$ & $99.98 \pm 15.13$ & $99.89 \pm 15.02$ \\
\hline Regular $(\mathrm{N}=356)$ & $99.64 \pm 14.48$ & $100.61 \pm 14.47$ & $100.91 \pm 14.16$ \\
\hline Frequent $(\mathrm{N}=389)$ & $100.73 \pm 15.23$ & $100.82 \pm 15.99$ & $100.24 \pm 15.39$ \\
\hline \multicolumn{4}{|l|}{ Tea consumption } \\
\hline Never $(\mathrm{N}=912)$ & $101.47 \pm 14.31^{\mathrm{b}, \mathrm{c,d}}$ & $101.42 \pm 14.28^{\mathrm{c}, \mathrm{d}}$ & $100.62 \pm 20.42$ \\
\hline Occasional $(\mathrm{N}=667)$ & $99.45 \pm 14.31^{\mathrm{a}}$ & $99.49 \pm 14.28$ & $100.32 \pm 15.02$ \\
\hline $\operatorname{Regular}(\mathrm{N}=103)$ & $97.06 \pm 14.21^{\mathrm{a}}$ & $97.15 \pm 14.17^{\mathrm{a}}$ & $98.11 \pm 14.94$ \\
\hline Frequent $(\mathrm{N}=58)$ & $95.17 \pm 14.23^{\mathrm{a}}$ & $95.05 \pm 14.19^{\mathrm{a}}$ & $97.21 \pm 15.34$ \\
\hline \multicolumn{4}{|l|}{ Women } \\
\hline \multicolumn{4}{|l|}{ Coffee consumption } \\
\hline Never $(\mathrm{N}=615)$ & $96.91 \pm 16.58$ & $96.09 \pm 16.42$ & $95.12 \pm 25.02$ \\
\hline Occasional $(\mathrm{N}=491)$ & $95.69 \pm 15.67$ & $95.19 \pm 15.56$ & $94.83 \pm 15.97$ \\
\hline $\operatorname{Regular}(\mathrm{N}=452)$ & $95.14 \pm 15.86$ & $95.75 \pm 15.48$ & $95.91 \pm 15.55$ \\
\hline Frequent $(\mathrm{N}=525)$ & $94.95 \pm 15.86$ & $94.89 \pm 17.23$ & $95.47 \pm 17.00$ \\
\hline \multicolumn{4}{|l|}{ Tea consumption } \\
\hline Never $(\mathrm{N}=819)$ & $95.90 \pm 15.57$ & $95.90 \pm 15.58$ & $95.46 \pm 20.42$ \\
\hline Occasional $(\mathrm{N}=965)$ & $95.72 \pm 15.32$ & $95.71 \pm 15.33$ & $95.73 \pm 15.02$ \\
\hline $\operatorname{Regular}(\mathrm{N}=198)$ & $94.58 \pm 15.18$ & $94.58 \pm 15.19$ & $94.58 \pm 14.94$ \\
\hline Frequent $(\mathrm{N}=101)$ & $91.86 \pm 15.33$ & $91.88 \pm 15.42$ & $92.54 \pm 15.34$ \\
\hline \multicolumn{4}{|c|}{$\begin{array}{l}\text { *Data presented as adjusted mean } \pm \text { SD. Model } 1 \text { was adjusted for age, ethnicity, smoking status, } \\
\text { alcohol intake, physical activity level, the diet quality index and, total calorie intake. The coffee } \\
\text { analyses were also adjusted for the frequency of tea consumption, and the tea analyses were ad- } \\
\text { justed for the frequency of coffee consumption. Model } 2 \text { adjusted for covariates in Model } 1+\text { caf- } \\
\text { feine intake. Model } 3 \text { adjusted for covariates in Model } 2 \text { + whitener and sweetener additive use. } \\
\text { 'Significantly different from the 'never' group }(\mathrm{p}<0.05) \text {. } \\
\text { 'Significantly different from the 'occasional' group }(\mathrm{p}<0.05) \text {. } \\
\text { 'Significantly different from the 'regular' group }(\mathrm{p}<0.05) \text {. } \\
\text { 'Significantly different from the 'frequent' group }(\mathrm{p}<0.05) \text {. }\end{array}$} \\
\hline
\end{tabular}

unclear at this time. The fact that tea consumption was associated with obesity while coffee consumption was not cannot be explained by caffeine content since tea contains as much caffeine as coffee [32]. This might be explained by other chemical ingredients included in tea such as catechins, which have been shown to increase lipid metabolism in an animal model [33] To our knowledge, this is the first study to investigate the association between coffee or tea consumption and obesity after adjusting for different additives. The negative relationships between tea consumption and BMI or WC that were observed in men were eliminated after controlling for the sweetener and whitener additives. This suggests that the inverse association between tea consumption and obesity measures observed in men was explained by additive use. It is also possible that the abundant groups of polyphenol components in tea that may positively impact obesity [34] are altered when tea is consumed with additives. There are analogous findings that support such a claim. For instance, the beneficial effects of cacao on cardiovascular health disappear when cacao is combined with dairy products [35].
Although frequent tea consumption was associated with a lower BMI and WC in men, it is noteworthy that few American men benefit from such an effect. Only $9.3 \%$ of the men in this study reported drinking at least 5 cups of tea per week, and only $3.3 \%$ reported drinking 2 cups per day. It is possible that frequent tea drinkers have other specific lifestyle behaviors that also impact their obesity level [36]. However, in this study the smoking, alcohol, physical activity and dietary variables were not more favorable within the men who frequently drank tea.

Surprisingly, the use of calorically rich coffee and tea whiteners such as cream ( $29 \mathrm{kcal}$ per tablespoon) and milk ( $\sim 9$ kcal per tablespoon) [37] were not associated with greater $\mathrm{BMI}$ or WC values within coffee and tea drinkers. In contrast, sweeteners had an independent association on BMI in both sexes and on WC in men; however, these associations were in the opposite direction to what would be expected. For example, men who added sugar/honey to their coffee/tea had a mean BMI value that was $1.0 \mathrm{~kg} / \mathrm{m}^{2}$ lower than that of men who did not add sweeteners to their coffee/tea. These results 
Table 5. Association between whitener and sweetener use with BMI and waist circumference (WC) in coffee and/or tea drinkers*

\begin{tabular}{llc}
\hline & BMI, kg/m $\mathrm{m}^{2}$ & WC, $\mathrm{cm}$ \\
\hline Men & & \\
Whiteners & & \\
None $(\mathrm{N}=704)$ & $27.5 \pm 18.3$ & $99.1 \pm 32.9$ \\
Only milk $(\mathrm{N}=370)$ & $27.0 \pm 13.6$ & $98.1 \pm 26.3$ \\
Only cream $(\mathrm{N}=98)$ & $27.6 \pm 7.1$ & $98.4 \pm 15.7$ \\
Both $(\mathrm{N}=293)$ & $27.3 \pm 12.5$ & $98.5 \pm 23.7$ \\
& & \\
Sweeteners & & \\
None $(\mathrm{N}=384)$ & $27.1 \pm 14.5^{\mathrm{b}, \mathrm{c}}$ & $97.4 \pm 27.6^{\mathrm{b}}$ \\
Only artificial sweetener $(\mathrm{N}=174)$ & $28.8 \pm 10.4^{\mathrm{a}, \mathrm{c}}$ & $102.1 \pm 20.8^{\mathrm{a}, \mathrm{c}}$ \\
Only sugar/honey $(\mathrm{N}=612)$ & $26.1 \pm 16.8^{\mathrm{a}, \mathrm{b}, \mathrm{d}}$ & $94.9 \pm 30.3^{\mathrm{b}, \mathrm{d}}$ \\
Both $(\mathrm{N}=295)$ & $27.7 \pm 12.5^{\mathrm{c}}$ & $99.7 \pm 23.8^{\mathrm{c}}$ \\
\hline Women & & \\
Whiteners & & \\
None $(\mathrm{N}=744)$ & & \\
Only milk $(\mathrm{N}=516)$ & $28.1 \pm 20.2$ & $94.7 \pm 32.3$ \\
Only cream $(\mathrm{N}=130)$ & $27.0 \pm 17.3$ & $92.7 \pm 29.3$ \\
Both $(\mathrm{N}=358)$ & $27.9 \pm 11.1$ & $94.1 \pm 24.3$ \\
& $27.7 \pm 14.6$ & $93.2 \pm 24.8$ \\
Sweeteners & & \\
None $(\mathrm{N}=401)$ & $28.8 \pm 13.3^{\mathrm{a}, \mathrm{c}}$ & $95.4 \pm 25.4$ \\
Only artificial sweetener $(\mathrm{N}=248)$ & $92.5 \pm 30.9$ \\
Only sugar/honey $(\mathrm{N}=700)$ & $28.0 \pm 15.6^{\mathrm{c}}$ & $94.4 \pm 28.0$ \\
Both $(\mathrm{N}=399)$ & & \\
\hline
\end{tabular}

$*$ Data presented as adjusted mean \pm SD. Analyses adjusted for type the mean number of cups of coffee and tea consumed per day, age, ethnicity, smoking status, alcohol intake, caffeine, physical activity level, diet quality index and total caloric intake. Sweetener use was also adjusted for in the whitener analyses, and whitener use was also adjusted for in the sweetener analyses.

${ }^{a}$ Significantly different from the group adding no sweetener $(\mathrm{p} \leq 0.05)$ ${ }^{\mathrm{b}}$ Significantly different from the group adding artificial sweetener $(\mathrm{p} \leq 0.05)$. 'Significantly different from the group adding sugar/honey $(\mathrm{p} \leq 0.05)$. ${ }^{\mathrm{d}}$ Significantly different from the group adding both artificial sweetener and sugar/honey $(\mathrm{p} \leq 0.05)$.

are consistent with the findings of the only other group of researchers who have examined the association between additive use and obesity. This previous study was limited to men and reported that those who added sugar/honey to their coffee/tea had a mean BMI value that was $1.1 \mathrm{~kg} / \mathrm{m}^{2}$ lower than those who did not add sugar/honey [24]. Taken together, these findings suggest that the use of caloric additives in coffee and tea is not a significant positive determinant of obesity.

While the caloric additives (milk, cream and sugar/honey) were not associated with BMI and $\mathrm{WC}$ in a positive manner, the same was not true for artificial sweeteners, a calorie-free additive. For example, women who added artificial sweetener to their coffee/tea had a $1.7 \mathrm{~kg} / \mathrm{m}^{2}$ higher BMI, and men who added artificial sweetener to their coffee/tea had a $4.7 \mathrm{~cm}$ higher WC compared to those who did not add any sweetener to their coffee/tea. These findings are consistent with those of
Bellisle et al. [38] who reported in a cross-sectional study that men and women who used artificial sweeteners had a higher BMI and waist-to-hip ratio. The unexpected relations between artificial sweetener use and obesity measures observed in the present study and by Bellisle et al. [38] might reflect the crosssectional designs of these studies and the uncertainty about the temporariness of these associations. Indeed, the use of artificial sweeteners might be a strategy that is adopted by overweight and obese individuals to help achieve weight control, and thus the higher BMI and WC values may have preceded the use of artificial sweeteners in our study and not the reverse. Furthermore, some studies have report that the use of artificial sweeteners could stimulate appetite and therefore increase daily energy intake $[39,40]$. There are other possible explanations for the unexpected associations between the additives and obesity measures observed in this study. Namely, other hot beverages, such as calorically rich gourmet coffee and tea (300-800 kcal [41]), have become popular in the USA in the last decade [42]. Consequently, individuals who crave rich and/or sweet hot beverages may choose these gourmet coffees instead of regular brewed coffee/tea loaded with additives.

The main strengths of this study include the use of a large sample of adults, the investigation of the two main types of hot beverages consumed and the consideration of additives. The major limitation of this study was the cross-sectional design, which makes it impossible to disentangle the causeand-effect association between the study variables with reverse causation being highly plausible. Furthermore, based on the questionnaire used, it was not possible to separately assess additives included in coffee versus tea, the portion size of the hot beverages, the volume of additives used, the coffee/tea type or the brewing process. Finally, the variables used to assess nutrition and physical activity in this study were selfreported and subject to recall and social desirability biases. Thus, residual confounding may have been present.

In summary, this cross-sectional study suggests that the frequency of coffee consumption was not associated with BMI or WC while frequent tea consumption was associated with a lower BMI and WC in men. However, this association was no longer significant after adjusting for additive use, suggesting that additive use in large measures explains the association between tea consumption and obesity. The use of artificial sweeteners was associated with larger BMI values in both men and women and larger WC values in men. This later observation likely reflects the cross-sectional nature of the study and not a cause-and-effect relationship between artificial sweetener use and obesity. Prospective studies are needed to investigate the temporal occurrence of coffee and tea additive use and obesity.

\section{Disclosure}

The authors declared no conflict of interest. 


\section{References}

1 National Coffee Association: National Coffee Drinking Trends New York 2008. Available from www.ncausa.org (accessed January 12, 2010).

2 Bleich SN, Wang YC, Wang Y, Gortmaker SL: Increasing consumption of sugar-sweetened beverages among us adults: 1988-1994 to 1999-2004. Am J Clin Nutr 2009;89:372-381.

$\checkmark 3$ Higdon JV, Frei B: Coffee and health: a review of recent human research. Crit Rev Food Sci Nutr 2006;46:101-123.

4 Schneider C, Segre T: Green tea: potential health benefits. Am Fam Physician 2009;79:591-594.

$\checkmark 5$ Greenberg JA, Axen KV, Schnoll R, Boozer CN Coffee, tea and diabetes: the role of weight loss and caffeine. Int J Obes (Lond) 2005;29:1121-1129.

6 Dellalibera O, Lemaire B, Lafay S: Le svetol, un extrait de cafe vert decafeine, induit une perte de poids et augmente le ratio masse maigre sure masse grasse chez des volontarires en surcharge ponderale. Phytotherapie 2006;44:194-197.

7 Han LK, Takaku T, Li J, Kimura Y, Okuda H: Anti-obesity action of Oolong tea. Int J Obes Relat Metab Disord 1999;23:98-105.

8 He RR, Chen L, Lin BH, Matsui Y, Yao XS, Kurihara $\mathrm{H}$ : Beneficial effects of oolong tea consumption on diet-induced overweight and obese subjects. Chin J Integr Med 2009;15:34-41.

9 Thom E: The effect of chlorogenic acid enriched coffee on glucose absorption in healthy volunteers and its effect on body mass when used long-term in overweight and obese people. J Int Med Res 2007; 35:900-908.

10 Westerterp-Plantenga M, Diepvens K, Joosen AM, Berube-Parent S, Tremblay A: Metabolic effects of spices, teas, and caffeine. Physiol Behav 2006;89: 85-91.

11 Rosengren A, Dotevall A, Wilhelmsen L, Thelle D, Johansson S: Coffee and incidence of diabetes in Swedish women: a prospective 18-year follow-up study. J Intern Med 2004;255:89-95.

12 Tuomilehto J, Hu G, Bidel S, Lindstrom J, Jousilahti P: Coffee consumption and risk of type 2 diabetes mellitus among middle-aged Finnish men and women. JAMA 2004;291:1213-1219.

13 van Dam RM, Feskens EJ: Coffee consumption and risk of type 2 diabetes mellitus. Lancet 2002; 360:1477-1478.

14 Egger G, Cameron-Smith D, Stanton R: The effectiveness of popular, non-prescription weight loss supplements. Med J Aust 1999;171:604-608.

15 Salazar-Martinez E, Willett WC, Ascherio A, Manson JE, Leitzmann MF, Stampfer MJ, Hu FB: Coffee consumption and risk for type 2 diabetes mellitus. Ann Intern Med 2004;140:1-8.

16 Cameron AJ, Dunstan DW, Owen N, Zimmet PZ, Barr EL, Tonkin AM, Magliano DJ, Murray SG, Welborn TA, Shaw JE: Health and mortality consequences of abdominal obesity: Evidence from the AusDiab study. Med J Aust 2009;191:202-208.
7 Balk L, Hoekstra T, Twisk J: Relationship between long-term coffee consumption and components of the metabolic syndrome: the Amsterdam Growth And Health Longitudinal Study. Eur J Epidemiol 2009;24:203-209.

18 Hino A, Adachi H, Enomoto M, Furuki K, Shigetoh Y, Ohtsuka M, Kumagae S, Hirai Y, Jalaldin A, Satoh A, Imaizumi T: Habitual coffee but not green tea consumption is inversely associated with metabolic syndrome: an epidemiological study in a general Japanese population. Diabetes Res Clin Pract 2007;76:383-389.

19 Wu CH, Lu FH, Chang CS, Chang TC, Wang RH, Chang CJ: Relationship among habitual tea consumption, percent body fat, and body fat distribution. Obes Res 2003;11:1088-1095.

20 Bracco D, Ferrarra JM, Arnaud MJ, Jequier E, Schutz Y: Effects of caffeine on energy metabolism, heart rate, and methylxanthine metabolism in lean and obese women. Am J Physiol 1995;269: E671-678.

21 Gregersen NT, Bitz C, Krog-Mikkelsen I, Hels O, Kovacs EM, Rycroft JA, Frandsen E, Mela DJ, Astrup A: Effect of moderate intakes of different tea catechins and caffeine on acute measures of energy metabolism under sedentary conditions. Br J Nutr 2009:1-8.

22 Westerterp-Plantenga MS, Lejeune MP, Kovacs EM: Body weight loss and weight maintenance in relation to habitual caffeine intake and green tea supplementation. Obes Res 2005;13:1195-1204.

23 Acheson KJ, Zahorska-Markiewicz B, Pittet P, Anantharaman K, Jequier E: Caffeine and coffee: their influence on metabolic rate and substrate utilization in normal weight and obese individuals. Am J Clin Nutr 1980;33:989-997.

24 Gyntelberg F, Hein HO, Suadicani P: Sugar in coffee or tea and risk of obesity: a neglected issue. Int J Food Sci Nutr 2009:1-9.

25 National Center for Health Statistics: 2001-2002 National Health And Nutrition Examination Survey (NHANES). Hyattsville, MD. Available from: www.cdc.gov/nchs/about/major/nhanes/ currentnhanes.htm (accessed March 20, 2010).

26 National Center for Health Statistics: 1999-2000 National Health And Nutrition Examination Survey (NHANES). Hyattsville, MD. Available from: www.cdc.gov/nchs/about/ major/nhanes/ currentnhanes.htm (accessed March 20, 2010).

27 Beer-Borst S, Amado R: Validation of a self-administered 24-hour recall questionnaire used in a largescale dietary survey. Z Ernährungswiss 1995;34: 183-189.
28 U.S. Department of Health and Human Services. USDA: Dietary guidelines for Americans, 6th ed. Washington D.C., 2005. Available from: $w w w$. health.gov/dietaryguidelines/dga2005/document/ default.htm (accessed August 16, 2010).

29 Soriguer F, Rojo-Martinez G, de Antonio IE: Coffee consumption and type 2 diabetes mellitus. Ann Intern Med 2004:141:321-323.

30 Monterrosa AE, Haffner SM, Stern MP, Hazuda HP: Sex difference in lifestyle factors predictive of diabetes in Mexican-Americans. Diabetes Care 1995; 18:448-456.

1 Ross CE, Bird CE: Sex stratification and health lifestyle: consequences for men's and women's perceived health. J Health Soc Behav 1994;35:161-178.

\$2 Barone JJ, Roberts HR: Caffeine consumption. Food Chem Toxicol 1996;34:119-129.

33 Ito Y, Ichikawa T, Morohoshi Y, Nakamura T, Saegusa Y, Ishihara K: Effect of tea catechins on body fat accumulation in rats fed a normal diet. Biomed Res 2008;29:27-32.

34 Lee BL, Ong CN: Comparative analysis of tea catechins and theaflavins by high-performance liquid chromatography and capillary electrophoresis. J Chromatogr A 2000;881:439-447.

35 Serafini M, Bugianesi R, Maiani G, Valtuena S, De Santis S, Crozier A: Plasma antioxidants from chocolate. Nature 2003;424:1013.

36 Yang YC, Lu FH, Wu JS, Wu CH, Chang CJ: The protective effect of habitual tea consumption on hypertension. Arch Intern Med 2004;164:1534-1540.

37 United States Department of Agriculture (USDA) USDA National Nutrient Database for Standard Reference, 2008. Available from www.nal.usda.gov/ fnic/foodcomp/search (accessed March 12, 2010).

38 Bellisle F, Altenburg de Assis MA, Fieux B, Preziosi P, Galan P, Guy-Grand B, Hercberg S: Use of 'light' foods and drinks in French adults: biological, anthropometric and nutritional correlates. J Hum Nutr Diet 2001; 14:191-206.

39 Bellisle FDrewnowski A: Intense sweeteners, energy intake and the control of body weight. Eur J Clin Nutr, 2007:61; 691-700.

40 Swithers SE, Martin AA, Davidson TL: Highintensity sweeteners and energy balance. Physiol Behav 2010;100: 55-62.

41 National Coffee Association of USA: National coffee drinking trends 2002. Available from $w w w$. ncausa.org (accessed January 12, 2010).

42 Shields DH, Corrales KM, Metallinos-Katsaras E: Gourmet coffee beverage consumption among college women. J Am Diet Assoc 2004;104:650-653. 